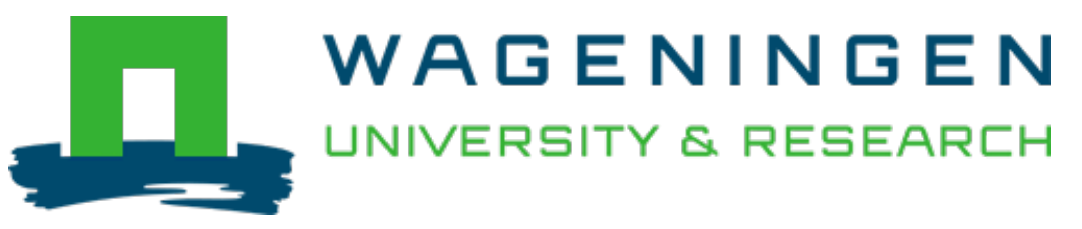

\author{
Improving resource efficiency in the food industry by using non-conventional \\ intermediate products \\ Journal of Food Engineering \\ Jonkman, Jochem; Castiglioni, Alberto; Akkerman, Renzo; Padt, Albert \\ https://doi.org/10.1016/j.jfoodeng.2020.110198
}

This article is made publicly available in the institutional repository of Wageningen University and Research, under the terms of article $25 \mathrm{fa}$ of the Dutch Copyright Act, also known as the Amendment Taverne. This has been done with explicit consent by the author.

Article 25 fa states that the author of a short scientific work funded either wholly or partially by Dutch public funds is entitled to make that work publicly available for no consideration following a reasonable period of time after the work was first published, provided that clear reference is made to the source of the first publication of the work.

This publication is distributed under The Association of Universities in the Netherlands (VSNU) 'Article 25fa implementation' project. In this project research outputs of researchers employed by Dutch Universities that comply with the legal requirements of Article $25 \mathrm{fa}$ of the Dutch Copyright Act are distributed online and free of cost or other barriers in institutional repositories. Research outputs are distributed six months after their first online publication in the original published version and with proper attribution to the source of the original publication.

You are permitted to download and use the publication for personal purposes. All rights remain with the author(s) and / or copyright owner(s) of this work. Any use of the publication or parts of it other than authorised under article $25 \mathrm{fa}$ of the Dutch Copyright act is prohibited. Wageningen University \& Research and the author(s) of this publication shall not be held responsible or liable for any damages resulting from your (re)use of this publication.

For questions regarding the public availability of this article please contact openscience.library@,wur.nl 


\title{
Improving resource efficiency in the food industry by using non-conventional intermediate products
}

\author{
Jochem Jonkman a , Alberto Castiglioni ${ }^{\mathrm{a}}$, Renzo Akkerman ${ }^{\mathrm{a}}$, Albert van der Padt ${ }^{\mathrm{b}, \mathrm{c}, *}$ \\ a Operations Research and Logistics Group, Wageningen University, PO Box 8130, 6700 EW, Wageningen, The Netherlands \\ ${ }^{\mathrm{b}}$ Food Process Engineering Group, Wageningen University, PO Box 8129, 6700 EV, Wageningen, The Netherlands \\ ${ }^{\mathrm{c}}$ FrieslandCampina, Stationsplein 4, 3818LE, Amersfoort, The Netherlands
}

\section{A R T I C L E I N F O}

\section{Keywords:}

Optimisation

Mild fractionation

Product selection

Process selection

Food industry

\begin{abstract}
A B S T R A C T
In the food industry, a wide range of consumer products is produced by blending together intermediate products. These intermediates are often purified extracts from agro-materials. The purification processes guarantee a standard quality and broad applicability, but are resource intensive and lead to the production of low-value byproducts. Non-conventionally produced intermediates could avoid these drawbacks. Hence, a portfolio of intermediates can be sought that satisfies the requirements of the food industry while reducing resource use. After developing a mathematical programming approach for this decision problem, this article quantifies the effect of using non-conventional intermediates while considering production interdependencies and customer requirements. An illustrative case for the processing of legumes shows that mildly refined intermediates can be selected to cover the demand for the majority of considered products. While minimising cost, energy use and water use were reduced by $22 \%$ and $37 \%$, respectively. The case results indicate that using fractionation pathways leading to intermediates with lower purity provides opportunities for more resource-efficient production in food industry.
\end{abstract}

\section{Introduction}

The current food system is based on specialisation and efficiency in growing certain crops and raising cattle and poultry around the world. Cheap shipping enables manufactures and retailers to supply a large assortment variety of food products from all around the globe. However, almost every stage in the food chain is performed and optimised in isolation (Berardy et al., 2019). This resulted in a substantial environmental impact of the food chain. Overall, the production and consumption of food accounts for $31 \%$ of the global warming potential (Perrot et al., 2016). Therefore, improvement of the food chain is inevitable, moreover, not individual products must be taken into account, but focus must be put on product portfolios and eventually diets. Sabaté and Jehi (2019) describe four determinants to arrive at sustainable diets, the balance of: (a) animal versus plant origin, (b) processed versus whole foods, (c) imported versus in-season food, and finally (d) the fraction of food wasted (Sabaté and Jehi, 2019). This paper focuses on the second determinant, to what extent must a crop be processed to reduce the environmental impact for a certain product portfolio.
One route is by using systematic approaches for the integrated design of products and processes to arrive at more effective and sustainable production processes. Known from the field of chemical engineering (e.g. Charpentier, 2009), such approaches hold great potential for the food industry (Datta, 2016). However, the focus on producing a specific end product diverts attention from the full valorisation of the required raw materials (Kiskini et al., 2016).

Alternatively, approaches are adopted to increasingly valorise streams previously considered as a waste. There are many opportunities in this area, as shown by the review of Mirabella et al. (2014). Often these rely on extracting specific components from the waste stream for their high value or abundance, leaving the remainder of the stream unused (Kiskini et al., 2016). Hence, preventing the need for valorisation by avoiding the creation of such streams is considered more beneficial for the environment (Papargyropoulou et al., 2014).

However, another option is to change the composition and characteristics of ingredients and food products (Raak et al., 2017). The current food industry produces a wide range of consumer products by blending a limited set of intermediate products in various combinations and proportions. The intermediates used are often purified to guarantee a standard quality and broad applicability (van der Goot et al., 2016).

\footnotetext{
* Corresponding author at: Food Process Engineering Group, Wageningen University, PO Box 8129, 6700 EV, Wageningen, The Netherlands. E-mail address: albert.vanderpadt@wur.nl (A. van der Padt).
} 


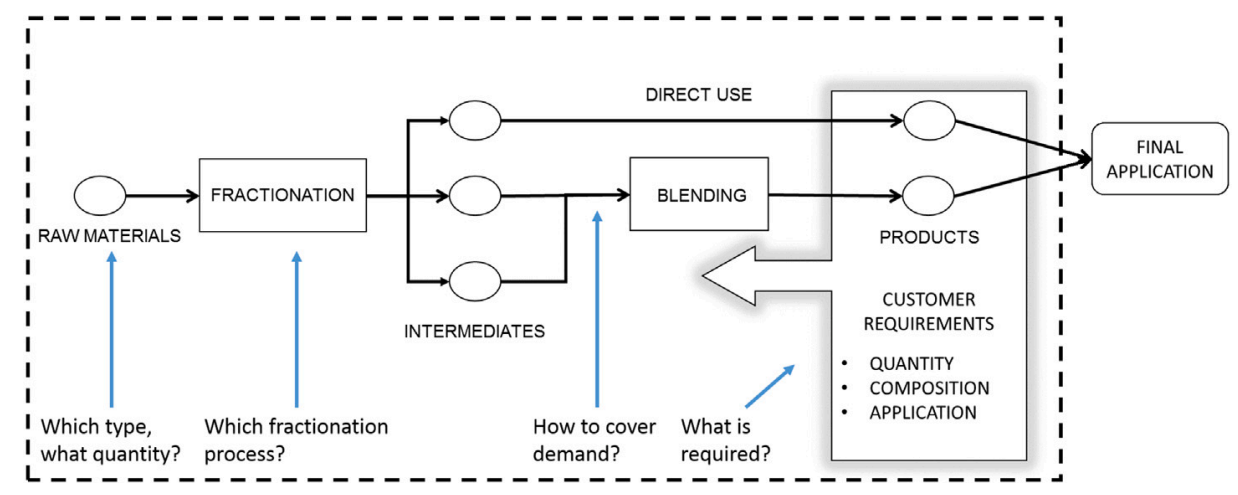

Fig. 1. Schematic representation of the production system and relevant considerations related to intermediate production. Source: Adapted from Castiglioni et al. (2018).

Table 1

Examples of final applications for the produced products, and their requirements.

\begin{tabular}{lll}
\hline Final application category & Examples of final applications & Examples of requirements \\
\hline Solid state foods & $\begin{array}{l}\text { Pasta enriched with veg-protein } \\
\text { Doughs for bakery application } \\
\text { Meat analogues }\end{array}$ & $\begin{array}{l}\text { High protein content and water holding capacity } \\
\text { Relatively high water holding capacity } \\
\text { Balanced content of protein and fibre, high water } \\
\text { holding capacity, medium-high protein solubility }\end{array}$ \\
Liquid state foods & Protein-rich drink & $\begin{array}{l}\text { Low fibre content, high protein solubility and low } \\
\text { viscosity }\end{array}$ \\
Gels & Low-fat fortified yogurt & Good gelation properties \\
Nutraceuticals & Dietary supplement & High purity and low moisture \\
Non-food application & Animal feed &
\end{tabular}

However, producing these intermediates from agro-materials comes at a cost. Often, more processing resources are required to extract intermediates with a higher purity. At the same time the total yield of the desired components is reduced (Tamayo Tenorio et al., 2018). Additionally, agro-materials consist of many components and isolating one of these from the rest greatly influences the quality of the remaining material (Jonkman et al., 2015).

Unlike many chemical products, the exact composition of a food product is often not specified. Although it has benefits for standardisation, chemical purity of the intermediates blended to produce the food product is therefore not a necessity. Authors such as Berghout et al. (2015) show how the production of less purified intermediates requires less resource-intensive, or mild, fractionation processes.

An intermediate producer could benefit from such processes and the resulting non-conventional intermediates but has to take into account the product requirements of its customers. A producer therefore has to decide how to meet customer demands based on product specifications resulting from the final application of the product. Hence, intermediates must be selected to produce, as well as the corresponding raw materials and fractionation processes required to produce these intermediates. These are required to fulfil the customer requirements. Intermediates can be used directly in the fulfilment of customer requirements, but can also be blended. Hence, a limited set of versatile intermediates can be produced to be blended according to customer requirements, or a wider variety of more customer-specific intermediates can be produced (Castiglioni et al., 2018). The production system with its considerations is illustrated in Fig. 1.

An intermediate producer will generally aim to minimise production costs, while also reducing resource use, such as energy and water consumption, in the context of reducing the environmental burden of production or dealing with a limited availability of resources. How exactly to do this is not straightforward, as there are many possibilities and different aspects to consider. A systematic approach is needed that combines the focus on end products from integrated product and process design with the focus on full valorisation of raw materials.

This article presents an approach to map and quantify the potential benefit of using non-conventional intermediates while considering requirements imposed by the final applications of these intermediates. The approach is illustrated using a case of legume processing. Proteinrich intermediates from legumes are used in a variety of foods such as bakery goods, meat alternatives, and drinks. However, legumes only partially consist of protein. Oil-rich legumes such as soy and lupin contain respectively $35 \%-40 \%$ and $39 \%-55 \%$ proteins (Tamayo Tenorio et al., 2018) and a carbohydrate-rich legume such as pea contains about $15 \%-32 \%$ proteins (Savage and Deo, 1989). Obtaining only the protein fraction does not valorise the remainder of the legumes, reducing the majority of these agro-materials to byproducts. This case is considered representative for other food industries in which intermediate producers conventionally focus on producing intermediates with a high chemical purity.

The illustrative case is further detailed in Section 2. An optimisation model for quantification of the case is presented in Section 3 together with the specific data used for the illustrative case. The results in Section 4 show that many customer requirements can be fulfilled with non-conventional intermediates while some customer requirements continue to require conventional intermediates. We discuss in Section 5 that non-conventional intermediates improve the resource use in food industry and that our approach enables the identification of gaps in the product portfolio. This could further improve the valorisation of agro-materials and reduce the production of waste and low-value byproducts. Final conclusions are presented in Section 6.

\section{Case definition}

We illustrate this using the theoretical case of a legume processor conventionally focused on producing protein-rich intermediates for its customers. These customers require protein-rich intermediates for applications in products that can be grouped into categories such as solid and liquid foods, nutraceuticals and supplements, and nonfood applications (Table 1). The conventional high-purity intermediates produced with conventional wet fractionation meet the customers' demand. However, the need for such high-purity intermediates is not obvious for many products. 

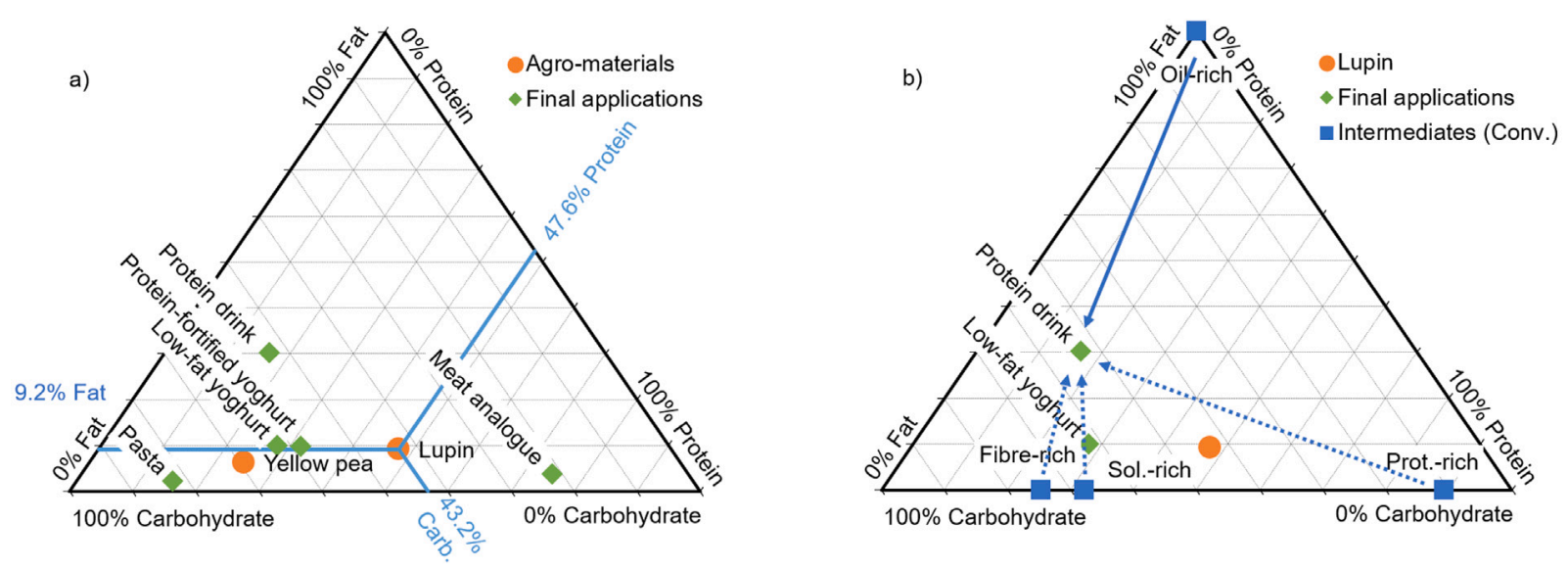

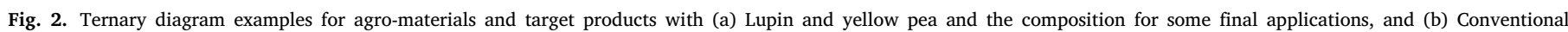
intermediates obtained from lupin processing with arrows indicating blending possibilities to achieve the composition of a target application.

Examples in the category of solid foods are pasta or pasta-like products. Pasta enriched with vegetable protein targets the need for protein suppletion in vegan or similar diets (Duranti, 2000) while also containing other components. In liquid foods, protein-rich drinks require the addition of protein without negatively affecting the viscosity of the drink by adding too much fibre. Supplements like protein powders for athletes, on the other hand, do require a higher degree of protein purity. Due to a wide variety of non-food applications, such as livestock feed, no strict targets are considered on the presence of other components besides protein.

Therefore, different intermediates can be produced and applied, using for instance dry fractionation or mild aqueous fractionation, which greatly reduce the water and energy consumption required to process agro-materials such as yellow pea (Pelgrom et al., 2014b) and lupin (Berghout et al., 2015).

The potential of a raw material and its intermediates for final applications can be mapped using ternary diagrams. In such a diagram, each axis represents one out of three compositional elements relevant to the investigation, which together equal to a constant. The diagram represents all possible combinations of these compositional elements.

In Fig. 2a, such a diagram is shown for the examples of lupin and yellow pea, plotting their dry-weight macro-nutrient composition (carbohydrate, fat, protein) on the three axes. For reference purposes, the composition is expressed in percentages. Hence, the coordinates of a point represent its composition of macro-nutrients, as is explicitly indicated for lupin in Fig. 2a. Intermediate products derived from these agro-materials have several final applications, such as in meat analogues and protein-fortified yoghurt, which are shown in the same figure. This representation shows how the compositions of different products relate to each other.

The intermediates produced from the raw materials can be indicated similarly, as well as possible blends of these identified to meet the requirements of the target products. This is illustrated in Fig. $2 \mathrm{~b}$, for the situation where an oil-rich intermediate can be blended with different quantities of fibre-rich, soluble-rich, and protein-rich intermediates to obtain a product meeting the compositional requirements for use in the application of a protein drink.

In ternary diagrams such as presented in Fig. 2, chemically pure products will appear in the extremes of the diagram. The target products depicted are not chemically pure, and several intermediates would have to be blended to obtain the required composition for final applications. Hence, producing chemically pure intermediates is not a strict necessity to obtain these desired target products. The ternary diagrams show that it is possible to produce the products listed in Table 1. A quantification approach using an optimisation model is presented in the following section.

\section{Quantification}

The selection of agro-materials, intermediates and fractionation pathways, as well as intermediate blending strategies is optimised using a Mixed-Integer Linear Programming (MILP) model based on Akkerman et al. (2010). Their model is extended to allow for (i) the selection of different fractionation pathways; (ii) the consideration of co-production of intermediates in intermediate portfolios, including related material balance relationships; and (iii) the consideration of the resource consumption of water and energy. In the mathematical notation, parameters or data are represented by a lowercase letter, while decision variables and index sets are represented by an uppercase letter.

\subsection{General model}

Given the considered raw materials $m \in M$ and fractionation pathways $f \in F$, the objective is to minimise the costs for raw materials and processing:

$\operatorname{Min} \sum_{m \in M} \sum_{f \in F} c_{m f} X_{m f}$

where $c_{m f}$ is the cost of sourcing and processing raw material $m$ using fractionation pathway $f$ and $X_{m f}$ is the quantity of material $m$ fractionated with pathway $f$. Each product $p \in P$ can consist of multiple intermediates $i \in I$, and the total demand $d_{p}$ of a product has to be met:

$$
\begin{aligned}
\sum_{i \in I} Z_{i p} & =1 \quad \forall p \in P \\
\sum_{m \in M} \sum_{f \in F} r_{m f i} X_{m f} & =\sum_{p \in P} d_{p} Z_{i p} \quad \forall i \in I
\end{aligned}
$$

Here, $r_{m f i}$ is the conversion parameter for material $m$ through pathway $f$ into intermediate $i$ and $Z_{i p}$ is the fraction of intermediate $i$ in product $p$. In the case that several intermediates $i$ are used in product $p$, the blending of intermediates is required:

$Y_{i p}= \begin{cases}1, & \text { if intermediate } i \text { is used in product } p \\ 0, & \text { otherwise. }\end{cases}$

$U_{p}= \begin{cases}1, & \text { if blending is required to produce product } p . \\ 0, & \text { otherwise. }\end{cases}$

$$
\begin{aligned}
Z_{i p} & \leq Y_{i p} \quad \forall i \in I, p \in P \\
\sum_{i \in I} Y_{i p}-1 & \leq n U_{p} \quad \forall p \in P \\
\sum_{p \in P} d_{p} U_{p} & \leq b
\end{aligned}
$$


Table 2

Quality bounds for the product according to the final applications.

\begin{tabular}{llr}
\hline Product description & Quality requirements & Demand ratio \\
\hline Pasta, protein enriched & Protein content $\geq 55 \%$, fibre content $\leq 68 \%$, other & 35 \\
& carbohydrates $\leq 10 \%$, fat content $\leq 23 \%$ \\
Dough & Protein content $\geq 65 \%$, protein content $\leq 90 \%$ & 100 \\
Meat analogue & Protein content $\geq 64 \%$, fibre content $\geq 18 \%$ & 2 \\
Low-fat yoghurt & Protein content $\geq 67 \%$, fat content $\leq 2 \%$ & 41 \\
Drink & Fibre content $\leq 5 \%$, fat content $\leq 10 \%$ & 5 \\
Nutraceutical & Protein content $\geq 78 \%$ & 2 \\
Non-food application & Flexible, no restrictions
\end{tabular}

The combination of Eqs. (6) and (7) relate fractions of intermediates used in a product to the binary variable indicating that blending is required. Eq. (8) ensures that the total quantity of products which require blending should not exceed the available blending capacity $b$.

Customer requirements may specify that intermediates of a specific origin are not allowed in a product, for instance to avoid allergens:

$Z_{i p} \leq a_{i p} \quad \forall i \in I, p \in P$

where $a_{i p}$ indicates to what level an intermediate $i$ may be used in product $p$. Additionally, for each component $k \in K$ the compositional requirement of product $p$ is enforced according to:

$q_{k p}^{\min } \leq \sum_{i \in I} q_{i k} Z_{i p} \quad \leq q_{k p}^{\max } \quad \forall k \in K, p \in P$

where $q_{i k}$ is the composition parameter of intermediate $i$ for component $k$, and $q_{k p}^{\min }$ and $q_{k p}^{\max }$ are the lower and upper limits for component $k$ in product $p$. This general formulation of the compositional requirements allows for product specifications by the customer, e.g. considering a range of values to be acceptable. In the cases where there is no lower or upper limit defined in the product specification, the values of the limits can be set to zero or one, respectively.

Resource consumption is described by:

$\sum_{m \in M} \sum_{f \in F} e_{m f} X_{m f}$

$\sum_{m \in M} \sum_{f \in F} w_{m f} X_{m f}$

where $e_{m f}$ and $w_{m f}$ are the respective energy and water consumption of processing material $m$ using fractionation pathway $f$. Eqs. (11) and (12) can also be used as objective functions, replacing or in combination with Eq. (1).

The model described above is generally applicable in this type of decision problem. For operational purposes, such as limiting the solution search space, additional constraints can be introduced. For instance, an intermediate producer can choose to limit the total number of intermediates selected, to manage the operational simplicity of the production operations or to adhere to possible storage capacity limitations:

$W_{i}= \begin{cases}1, & \text { if intermediate } i \text { is used. } \\ 0, & \text { otherwise }\end{cases}$

$\sum_{p \in P} Z_{i p} \leq n W_{i} \quad \forall i \in I$

$\sum_{i \in I} W_{i} \leq j$

$\sum_{i \in I} Y_{i p} \leq n \quad \forall p \in P$

where $j$ is the maximum number of intermediates the producer is willing or able to handle. Similarly, Eq. (16) functions as operational restriction to limit the total number of intermediates used in a product $p$ to the maximum of $n$. The general formulation of the model was applied to the illustrative case of a legume processor. In the case, a limited number of fractionation processes and intermediates relevant to the processor are considered, which are detailed below.
Table 3

Water use and energy use for processing based on Berghout et al. (2015), Schutyser et al. (2015), and Geerts et al. (2017a), costs estimated based on Berk (1992) and Apaiah and Hendrix (2005).

\begin{tabular}{lllll}
\hline Agro-material & Pathway & Water $(\mathrm{kg} / \mathrm{kg})$ & Energy $(\mathrm{MJ} / \mathrm{kg})$ & Cost $(€ /$ ton $)$ \\
\hline \multirow{4}{*}{ Lupin } & Conventional & 23.27 & 60.33 & 91.82 \\
& Aqueous & 15 & 50.31 & 70.45 \\
& Dry & 0 & 0.52 & 48.58 \\
& Combined & 4.95 & 17.13 & 55.87 \\
\multirow{4}{*}{ Pea } & Conventional & 12.5 & 60.55 & 85.02 \\
& Aqueous & 4.40 & 53.03 & 58.30 \\
& Dry & 0 & 0.52 & 48.58 \\
\hline
\end{tabular}

\subsection{Case data}

The list of final applications considered in the illustrative case, and specific restrictions to the intermediate products for each of these final applications is presented in Table 2. Customers' demand for the products are estimated based on the average demand for the final applications in the Netherlands (van Rossum et al., 2016), additionally assuming that all surplus intermediates can be directed to non-food applications. The demand for products is presented as a ratio, meaning a demand of 100 units (e.g. ton) of products for application in dough implies a demand of 2 units for application in nutraceuticals.

To produce the intermediates needed for these final applications, several conventional and mild fractionation processes can be used to convert yellow peas (Pelgrom et al., 2014b) and lupin (Berghout et al., 2015). In these fractionation processes, several process steps are executed to split the raw material into the desired fractions. A series of process steps combined forms a fractionation pathway, of which four are considered: conventional, aqueous, dry, and a combination of dry and aqueous (Fig. 3).

For each fractionation pathway, the water and energy consumption for processing, as well as the processing cost, are presented in Table 3. Each pathway leads to a portfolio of intermediates, i.e. producing one intermediate using the fractionation pathway implies coproducing other intermediates. The yield of each intermediate and the composition are given in Table 4.

The production of all required intermediates using the conventional processing of lupin was used as a base case for comparisons. An optimal selection of intermediates was determined while minimising cost, energy use, and water using Eqs. (1), (11) and (12) as objective functions, respectively. Additionally, the model was used to explore the relation between the minimal energy use that could be obtained and the maximum number of intermediates that could be selected.

\section{Optimisation results}

From the base case we observe that it is indeed possible to meet the customers' demand for all products using the intermediates obtained from the conventional processing of lupin. In the modelled case, a quantity of 4400 ton lupin is required, with an associated cost of $1812 \mathrm{k} €$ for sourcing and processing. Water use for the base case was 102 kton, and energy use totalled at 265 TJ. The total quantity of 


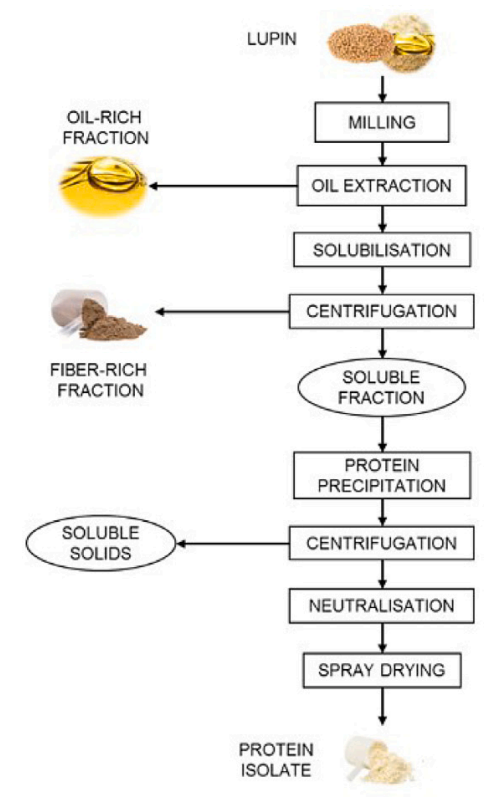

CONVENTIONAL

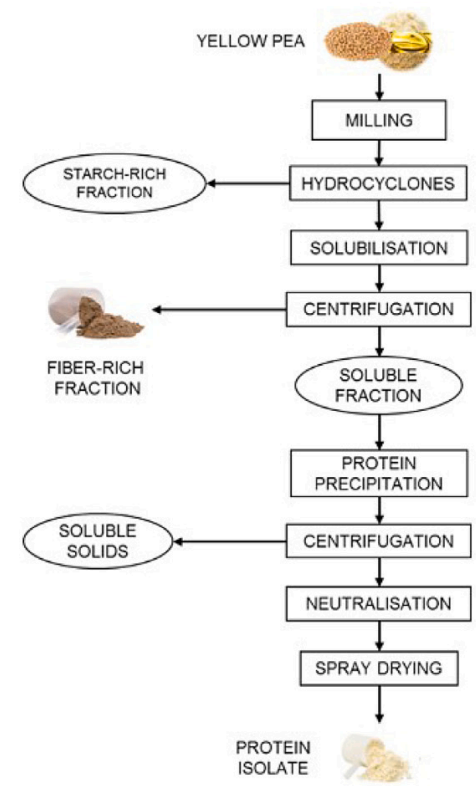

CONVENTIONAL

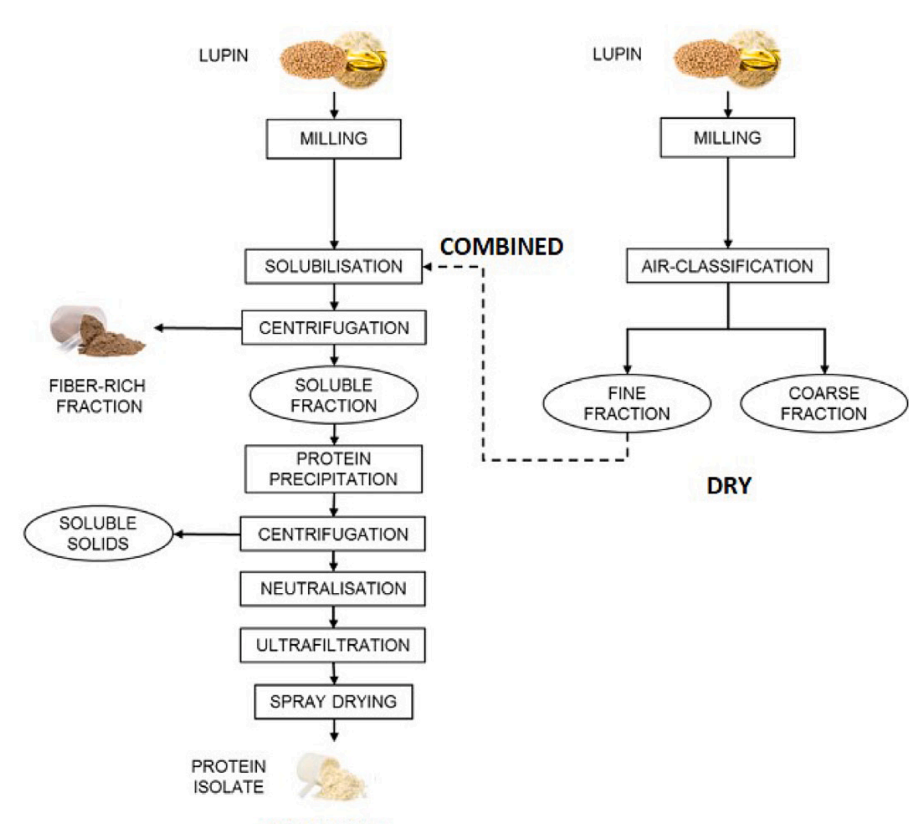

AQUEOUS

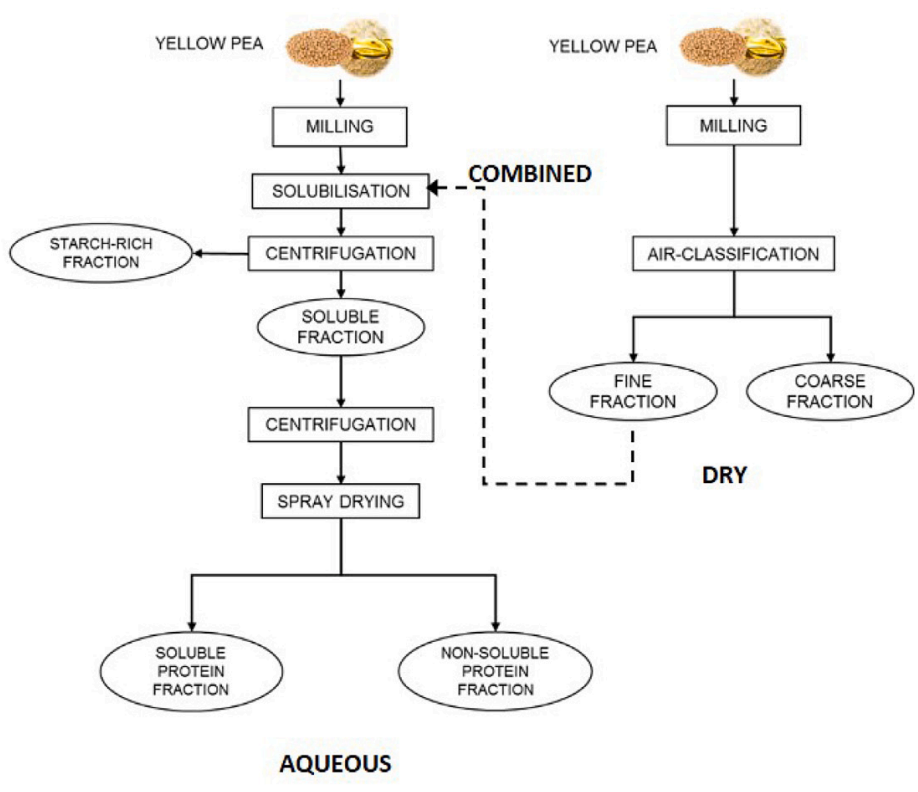

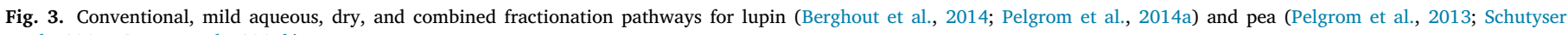
et al., 2015; Geerts et al., 2017b).

intermediates assigned to non-food by-products was 2462 ton. Results in the remainder of this section are reported relative to these figures.

Fig. 4 shows the performance indicators related to the optimal intermediate and pathway selection according to the different objectives to minimise cost, water use, and energy use. Optimal solutions for each of these objectives incorporate more intermediates than the four conventional intermediates in the base case. The fractionation pathways selected to produce these intermediates, the type of processed material and the ratio between these is presented in Fig. 5. These results show that incorporating non-conventional intermediates can benefit both on production cost and resource use.

\subsection{Resource optimisation}

Lowest cost was achieved using a total of seven intermediates to blend all the desired products. The introduction of non-conventional intermediates improved cost, water use, energy use, and by-product production with respectively $13 \%, 37 \%, 22 \%$, and $21 \%$. Consumption of raw materials was reduced by $9 \%$.

The blend of intermediates used to produce the required products is shown in Fig. 6 for the base case and the minimal cost scenario. A clear shift is observed in the fractions blended to produce the end products. In the base case, only conventional intermediates are used, while over $85 \%$ of the intermediates used in the minimised cost solution are non-conventional (see Fig. 5). Fig. 6 also shows that 
Table 4

Intermediate portfolios produced for lupin and pea per fractionation pathway. Yield and composition based on wet weight (ash and water content not shown, values from Berghout et al., 2015; Geerts et al., 2017a; Pelgrom et al., 2014b).

\begin{tabular}{|c|c|c|c|c|c|c|}
\hline Pathway & Fraction & $\begin{array}{l}\text { Yield } \\
(\mathrm{kg} / \mathrm{kg})\end{array}$ & $\begin{array}{l}\text { Fibre } \\
(w / w)\end{array}$ & $\begin{array}{l}\text { Protein } \\
(\mathrm{w} / \mathrm{w})\end{array}$ & $\begin{array}{l}\text { Carbohydrate } \\
(\mathrm{w} / \mathrm{w})\end{array}$ & $\begin{array}{l}\text { Fat } \\
(w / w)\end{array}$ \\
\hline \multicolumn{7}{|l|}{ (a) Lupin } \\
\hline \multirow[t]{3}{*}{ Conventional } & Oil-rich & 0.07 & 0 & 0 & 0 & 1 \\
\hline & Fibre-rich & 0.37 & 0.68 & 0.23 & 0 & 0 \\
\hline & Soluble & 0.27 & 0 & 0.28 & 0.59 & 0 \\
\hline \multirow{2}{*}{ Aqueous } & Soluble & 0.20 & 0 & 0.37 & 0.50 & 0 \\
\hline & Protein-rich & 0.29 & 0 & 0.80 & 0 & 0.07 \\
\hline \multirow[t]{2}{*}{ Dry } & Coarse & 0.67 & 0.37 & 0.32 & 0.14 & 0.06 \\
\hline & Fine & 0.33 & 0 & 0.49 & 0.35 & 0.07 \\
\hline $\begin{array}{l}\text { Combined } \\
\text { aqueous } \\
\text { and dry }\end{array}$ & Coarse & 0.67 & 0.37 & 0.32 & 0.14 & 0.06 \\
\hline Starting material & Pea & & 0.13 & 0.21 & 0.47 & 0.05 \\
\hline \multirow[t]{4}{*}{ Conventional } & Fibre-rich & 0.074 & 0.95 & 0 & 0 & 0 \\
\hline & Starch-rich & 0.42 & 0.31 & 0 & 0.64 & 0 \\
\hline & Sugar-rich & 0.18 & 0 & 0 & 0.87 & 0.08 \\
\hline & Protein-rich & 0.25 & 0 & 0.82 & 0.02 & 0.08 \\
\hline \multirow[t]{3}{*}{ Aqueous } & Carbohydr. & 0.66 & 0.23 & 0.04 & 0.66 & 0.01 \\
\hline & Sol. protein & 0.24 & 0.3 & 0.53 & 0.03 & 0.09 \\
\hline & Non-sol.prot. & 0.10 & 0.29 & 0.51 & 0.02 & 0.1 \\
\hline \multirow[t]{2}{*}{ Dry } & Coarse & 0.68 & 0.19 & 0.07 & 0.6 & 0.01 \\
\hline & Fine & 0.33 & 0.38 & 0.39 & 0.02 & 0.03 \\
\hline $\begin{array}{l}\text { Combined } \\
\text { aqueous } \\
\text { and dry }\end{array}$ & Coarse & 0.68 & 0.19 & 0.07 & 0.6 & 0.01 \\
\hline
\end{tabular}

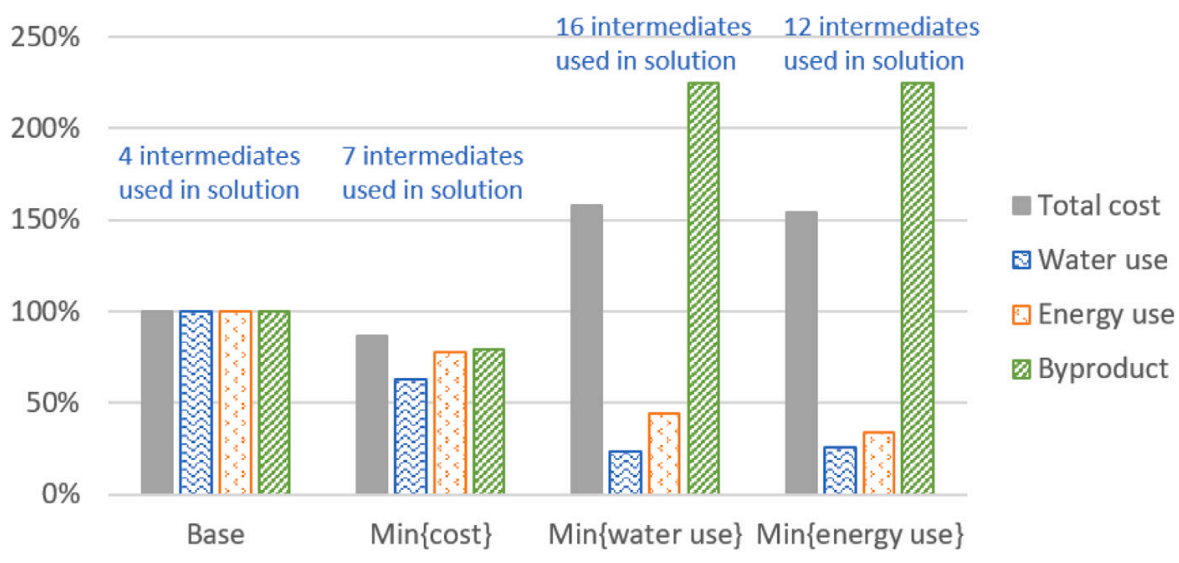

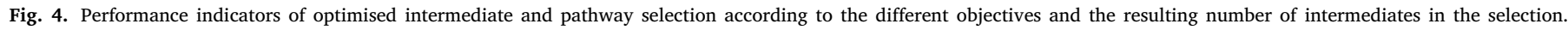

these non-conventional intermediates are in some cases combined with conventional intermediates to obtain the desired product composition.

\subsection{Resource use reduction $v$ s. number of intermediates}

Compared to the base case, the optimised selections of intermediates and pathways require an increased number of intermediates. This could lead to an increased operational complexity at the intermediate producer (e.g. due to the handling of all the intermediate flows, inventories, and blending operations). Hence, the relation was investigated between the total number of intermediates the producer is willing to handle and the savings in resource use. The right hand side of Eq. (15) was adjusted to limit the number of intermediates selected, iteratively minimising Eq. (11) subject to Eqs. (3)-(16).
No feasible solution is found for less than 4 intermediates $(j \leq 3)$ while the base case solution using conventional fractionation of lupin is selected when four intermediates are allowed $(j=4)$. Increasing the number of allowed intermediates does not yield a new selection of fractionation pathways and intermediates until at least six intermediates are allowed. At this point $(j=6)$, the non-conventional dry pathway is included besides the conventional pathway, as can be seen in Fig. 7 . This solution remains the optimal solution up to the point that eight intermediates are allowed $(j=8)$. Then, the dry pathway is replaced by the combined dry and aqueous pathway. This reduces the need for most conventional processing below a level of $0.2 \%$ and leads to large savings in water use and energy use (see Fig. 8). A new optimal solution is found when ten intermediates are allowed $(j=10)$, in which the dry 


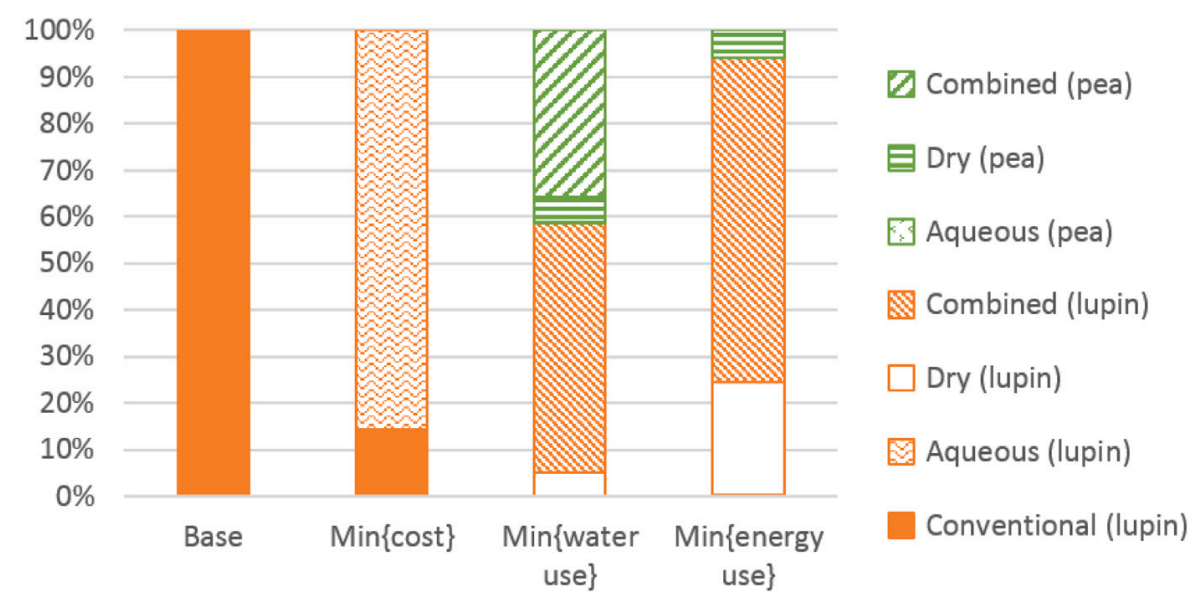

Fig. 5. Overview of the percentage of raw material processed using the selected fractionation pathways according to the different objectives.

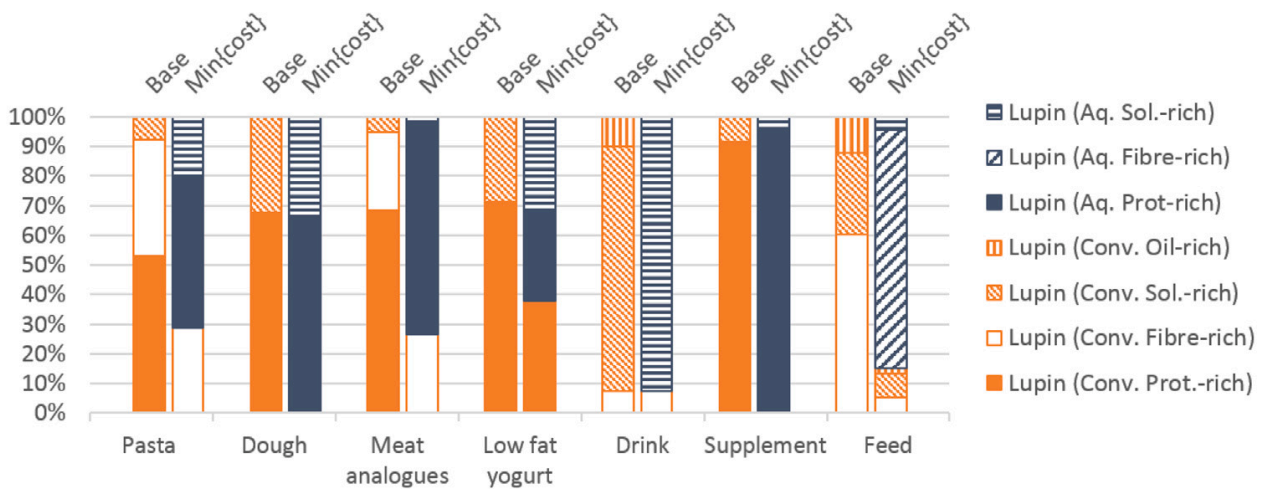

Fig. 6. Optimised blend of intermediates in products to fulfil customer demand.

pathway is introduced again besides the others. The minimal energy use in the case study is obtained using twelve intermediates $(j=12)$, at which point also dry processed pea is included in the minimum energy solution. These results show a potential trade-off between resource use and operational complexity at the intermediate producer.

\section{Discussion and implications}

The optimisation results show an overall reduction of resource use is possible by partially replacing conventional intermediates with non-conventional ones. This section discusses these results in more detail and highlights some implications for the make-up of the product portfolio and the design and set-up of production processes.

Fig. 4 shows a reduction of energy use and water use is possible to values as low as $34 \%$ and $23 \%$ of the base case. However, these reductions come at added cost and an increased number of intermediates that is assigned to non-food by-products. This is related to the large percentage of the dry and combined fractionation pathways selected in these scenarios (Fig. 5). These pathways lead to the co-production of a coarse intermediate which is considered to be of feed quality in the case. If this fraction could be of food quality, a broader product portfolio is needed to assign this intermediate to a food product.

Fig. 6 shows that the fractions assigned to the non-food product category (feed) in the minimised cost solution are mainly fibre-rich and other carbohydrate-rich fractions. This shows that the current product portfolio of the intermediate producer is short on applications for these intermediates. By identifying higher-value applications for these intermediates, it might be possible to further improve profitability.

Redefining the product specifications together with customers, or developing new products can improve the use of the fractions that are produced in excess. This supports the intermediate producer in finding cost-neutral or cost-beneficial ways for reducing energy and water consumption. For this purpose, the ternary diagrams are again a useful tool to map the area of interest in which new products are to be formulated, depending on the blending possibilities of the intermediates which are produced in excess in the current case.

In Fig. 9, the conventional and non-conventional intermediates obtainable from lupin are shown for this case study. Based on the results presented in Fig. 6, the intermediates currently assigned to the non-food product category are identified. Together, they span the area of interest in which new target products can be identified to valorise these non-conventional intermediates (highlighted area in Fig. 9).

A better understanding of the effect of processing on the composition of intermediates helps to identify better fractionation pathways. For example, in the case study, the representation with ternary diagrams shows that a small shift is required in the composition of one intermediate to overlap with the specification of a final application (illustrated in Fig. 10). Additionally, the diagram shows which two processing steps could be altered to achieve the desired target (i.e. air classification and fibre separation). For instance, Pelgrom et al. (2014a) shows how changing the process settings during air classification of lupin alters the obtained fractions, which is also indicated in Fig. 10. Such a change in process settings would alter the starting material for the fibre separation step and in turn shift the obtained fractions from the fibre separation step. Consequently, the parameters in the MILPmodel presented in Section 3 can be updated to include the alternative process settings and the optimal settings can be determined.

The case study results show how non-conventional intermediates could lead to a more resource-efficient production of mixed food products. Using non-pure intermediates enabled a reduction in costs, energy use, and water use. This would however lead to the use of 


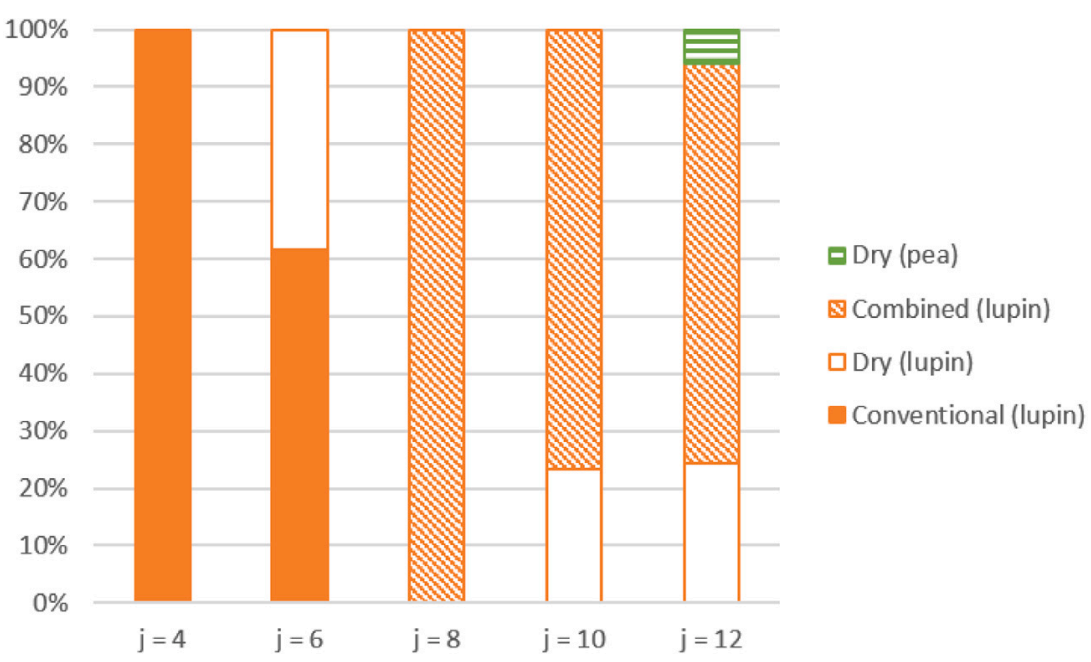

Fig. 7. Percentage of raw material processed using the selected fractionation pathways while minimising total energy use for different numbers $j$ of allowed intermediates.

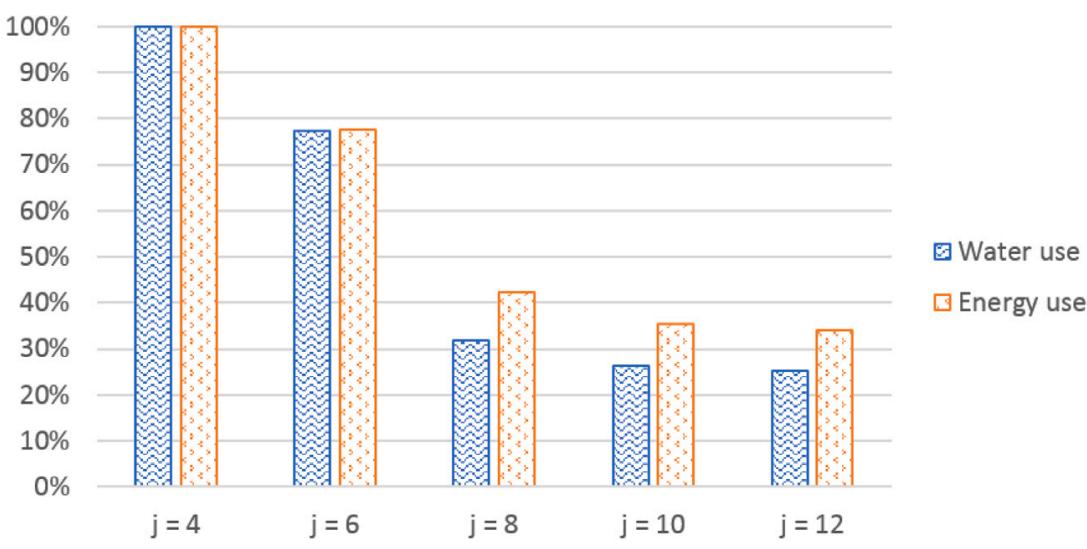

Fig. 8. Resource use of the optimal intermediate and pathway selection minimising total energy use for different numbers $j$ of allowed intermediates.

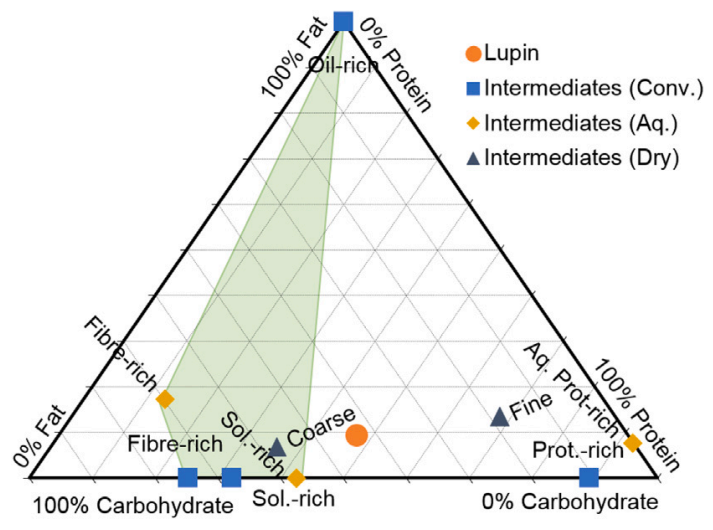

Fig. 9. Identification of the desired product composition requirements (shaded area) that can be obtained with the intermediates which are produced in excess in the case study.

more application-specific intermediates, which increases the operational complexity of an intermediate producer. Moreover, collaboration is required between an intermediate producer and their customers to identify and produce the optimal portfolio of intermediate products.

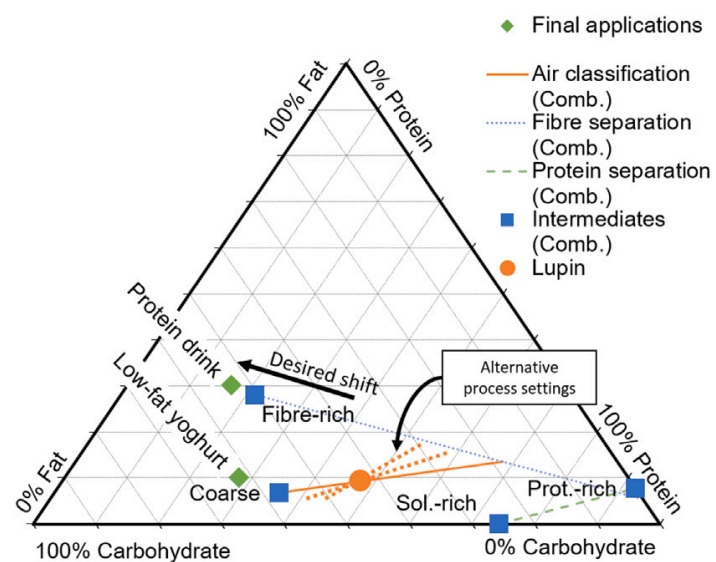

Fig. 10. Identification of opportunities for process improvement using the ternary diagrams.

Similar insights might be obtained for other agro-food industries, such as potato and dairy processors. Similar to the case study investigated in this paper, these and other agro-food industries convert raw 
materials into a range of intermediates which are used for a variety of final applications. The presented approach to map and quantify the potential benefit of using non-conventional intermediates is a promising tool for that purpose.

The analysis in this article is based upon the chemical characteristics of food products. In the case of food and other mixed consumer products, the final properties of a product are often not only determined by their chemical composition (Bongers, 2009; Dubbelboer et al., 2015). The techno-functional characteristics (e.g. water-holding capacity, emulsifying properties) of intermediates are not determined by single components, and production processes affect the final properties of a blend of intermediates (e.g. Geerts et al., 2017a; Garcia-Amezquita et al., 2018). The understanding of these interactions between intermediates and processing is limited (Datta, 2016). Although empirical knowledge is sometimes available in industry, this has often not been translated into numerical models (Monnet et al., 2019).

\section{Conclusion}

This article deals with the use of non-conventional intermediate products in the food industry. An approach is used to combine the focus on end products from integrated product and process design with a focus on the full valorisation of raw materials. Ternary diagrams are used to visually create an overview of the improvement opportunities stemming from the use of non-conventional intermediate products, and to identify improvement opportunities for process development. A general optimisation model is presented to quantify and optimise the effect of using non-conventional intermediates in the food industry. The model is applied to an illustrative case for the processing of legumes.

Results show that overall resource use in the food industry can be reduced through the use of non-conventional intermediates. In the case study, while total production costs were minimised, energy use and water use were reduced as well, by $22 \%$ and $37 \%$, respectively. The case results indicate that using fractionation pathways leading to intermediates with lower purity provides opportunities for more resource-efficient production in the food industry.

Having insight in the relation between composition and technical functionality of intermediates could enable the further reduction of resource use and valorisation of by-products in the production of mixed consumer products through the identification of novel intermediates and fractionation pathways. Recent work by Geerts et al. (2017a,b) and Monnet et al. (2019) take first steps linking product composition and product processing to techno-functional properties. Further studying the interaction between processing, intermediate composition, and product properties is a promising and much needed research avenue.

\section{Declaration of competing interest}

The authors declare that they have no known competing financial interests or personal relationships that could have appeared to influence the work reported in this paper.

\section{Acknowledgements}

This work was supported by the Institute for Sustainable Process Technology (the Netherlands) within the Mild Fractionation for Food cluster, project CM-20-01: Process Synthesis.

\section{References}

Akkerman, R., van der Meer, D., van Donk, D.P., 2010. Make to stock and mix to order: Choosing intermediate products in the food-processing industry. Int. J. Prod. Res. 48 (12), 3475-3492. http://dx.doi.org/10.1007/s00291-010-0223-2.

Apaiah, R.K., Hendrix, E.M.T., 2005. Design of a supply chain network for pea-based novel protein foods. J. Food Eng. 70 (3), 383-391. http://dx.doi.org/10.1016/j. jfoodeng.2004.02.043.
Berardy, A., Lynch, H., Wharton, C., 2019. Chapter 2 - food systems: Description and trends. In: Sabaté, J. (Ed.), Environmental Nutrition. Academic Press, pp. 27-40. http://dx.doi.org/10.1016/B978-0-12-811660-9.00002-3.

Berghout, J.A.M., Boom, R.M., van der Goot, A.J., 2014. The potential of aqueous fractionation of lupin seeds for high-protein foods. Food Chem. 159, 64-70. http: //dx.doi.org/10.1016/j.foodchem.2014.02.166.

Berghout, J.A.M., Pelgrom, P.J.M., Schutyser, M.A.I., Boom, R.M., van der Goot, A.J., 2015. Sustainability assessment of oilseed fractionation processes: A case study on lupin seeds. J. Food Eng. 150, 117-124. http://dx.doi.org/10.1016/j.jfoodeng.2014. 11.005.

Berk, Z., 1992. Technology of Production of Edible Flours and Protein Products from Soybeans. In: FAO Agricultural Bulletin, (97), Food and Agriculture Organization of the United Nations.

Bongers, P.M.M., 2009. Process and equipment design optimising product properties and attributes. Comput. Aided Chem. Eng. 26, 225-230. http://dx.doi.org/10.1016/ S1570-7946(09)70038-0.

Castiglioni, A., Jonkman, J., Akkerman, R., van der Padt, A., 2018. Selection of fractionation pathways and intermediates for mixed consumer products. Comput. Aided Chem. Eng. 43, 651-656. http://dx.doi.org/10.1016/B978-0-444-64235-6. 50116-9.

Charpentier, J.-C., 2009. Perspective on multiscale methodology for product design and engineering. Comput. Chem. Eng. 33 (5), 936-946. http://dx.doi.org/10.1016/j. compchemeng.2008.11.007.

Datta, A., 2016. Toward computer-aided food engineering: Mechanistic frameworks for evolution of product, quality and safety during processing. J. Food Eng. 176, 9-27. http://dx.doi.org/10.1016/j.jfoodeng.2015.10.010.

Dubbelboer, A., Janssen, J., Krijgsman, A., Zondervan, E., Meuldijk, J., 2015. Integrated product and process design for the optimization of mayonnaise creaminess. Comput. Aided Chem. Eng. 37, 1133-1138. http://dx.doi.org/10.1016/B978-0-444-635778.50034-6.

Duranti, M., 2000. Pasta enriched with vegetable proteins, Italy. EP 0997078 A2.

Garcia-Amezquita, L.E., Tejada-Ortigoza, V., Serna-Saldivar, S.O., Welti-Chanes, J., 2018. Dietary fiber concentrates from fruit and vegetable by-products: Processing, modification, and application as functional ingredients. Food Bioprocess Technol. 11 (8), 1439-1463. http://dx.doi.org/10.1007/s11947-018-2117-2.

Geerts, M.E.J., Mienis, E., Nikiforidis, C.V., van der Padt, A., van der Goot, A.J., 2017a. Mildly refined fractions of yellow peas show rich behaviour in thickened oil-inwater emulsions. Innov. Food Sci. Emerg. Technol. 41, 251-258. http://dx.doi.org/ 10.1016/j.ifset.2017.03.009.

Geerts, M.E.J., Strijbos, M., van der Padt, A., van der Goot, A.J., 2017b. Understanding functional properties of mildly refined starch fractions of yellow pea. J. Cereal Sci. 75, 116-123. http://dx.doi.org/10.1016/j.jcs.2017.03.025.

van der Goot, A.J., Pelgrom, P.J.M., Berghout, J.A.M., Geerts, M.E.J., Jankowiak, L., Hardt, N.A., Keijer, J., Schutyser, M.A.I., Nikiforidis, C.V., Boom, R.M., 2016. Concepts for further sustainable production of foods. J. Food Eng. 168, 42-51. http://dx.doi.org/10.1016/j.jfoodeng.2015.07.010.

Jonkman, J., Bloemhof, J.M., van der Vorst, J.G.A.J., van der Padt, A., 2015. A sustainability driven methodology for process synthesis in agro-food industry. Comput. Aided Chem. Eng. 37, 1289-1294. http://dx.doi.org/10.1016/B978-0444-63577-8.50060-7.

Kiskini, A., Zondervan, E., Wierenga, P.A., Poiesz, E., Gruppen, H., 2016. Using product driven process synthesis in the biorefinery. Comput. Chem. Eng. 91, 257-268. http://dx.doi.org/10.1016/j.compchemeng.2016.03.030.

Mirabella, N., Castellani, V., Sala, S., 2014. Current options for the valorization of food manufacturing waste: A review. J. Cleaner Prod. 65, 28-41. http://dx.doi.org/10. 1016/j.jclepro.2013.10.051.

Monnet, A.-F., Michon, C., Jeuffroy, M.-H., Blumenthal, D., 2019. Taking into account upstream variability of flours with processing variables in legume-enriched soft cakes: Conception of a multiobjective model for the monitoring of physical properties. Food Bioprocess Technol. 12 (4), 625-635. http://dx.doi.org/10.1007/ s11947-018-2230-2.

Papargyropoulou, E., Lozano, R., Steinberger, J.K., Wright, N., bin Ujang, Z., 2014. The food waste hierarchy as a framework for the management of food surplus and food waste. J. Cleaner Prod. 76, 106-115. http://dx.doi.org/10.1016/j.jclepro.2014.04. 020.

Pelgrom, P.J.M., Berghout, J.A.M., van der Goot, A.J., Boom, R.M., Schutyser, M.A.I., 2014a. Preparation of functional lupine protein fractions by dry separation. LWT - Food Sci. Technol. 59 (2P1), 680-688. http://dx.doi.org/10.1016/j.lwt.2014.06. 007.

Pelgrom, P.J.M., Boom, R.M., Schutyser, M.A.I., 2014b. Functional analysis of mildly refined fractions from yellow pea. Food Hydrocolloids 44, 12-22. http://dx.doi. org/10.1016/j.foodhyd.2014.09.001.

Pelgrom, P.J.M., Vissers, A.M., Boom, R.M., Schutyser, M.A.I., 2013. Dry fractionation for production of functional pea protein concentrates. Food Res. Int. 53 (1), 232-239. http://dx.doi.org/10.1016/j.foodres.2013.05.004.

Perrot, N., De Vries, H., Lutton, E., van Mil, H.G., Donner, M., Tonda, A., Martin, S., Alvarez, I., Bourgine, P., van der Linden, E., Axelos, M.A., 2016. Some remarks on computational approaches towards sustainable complex agri-food systems. Trends Food Sci. Technol. 48, 88-101. http://dx.doi.org/10.1016/j.tifs.2015.10.003. 
Raak, N., Symmank, C., Zahn, S., Aschemann-Witzel, J., Rohm, H., 2017. Processingand product-related causes for food waste and implications for the food supply chain. Waste Manag. 61, 461-472. http://dx.doi.org/10.1016/j.wasman.2016.12. 027.

van Rossum, C.T.M., Buurma-Rethans, E.J.M., Vennemann, F.B.C., Beukers, M., Brants, H.A.M., De Boer, E.J., Ocké, M.C., 2016. The diet of the Dutch: Results of the first two years of the dutch national food consumption survey 2012-2016. Technical Report, Rijksinstituut voor Volksgezondheid en Milieu RIVM.

Sabaté, J., Jehi, T., 2019. Chapter 10 - determinants of sustainable diets. In: Sabaté, J. (Ed.), Environmental Nutrition. Academic Press, pp. 181-196. http://dx.doi.org/ 10.1016/B978-0-12-811660-9.00012-6.
Savage, G.P., Deo, S., 1989. The nutritional value of peas (pisum sativum): A literature review. In: Nutrition Abstracts and Reviews (Series A), Vol. 59. (2), pp. 66-88.

Schutyser, M.A.I., Pelgrom, P.J.M., van der Goot, A.J., Boom, R.M., 2015. Dry fractionation for sustainable production of functional legume protein concentrates. Trends Food Sci. Technol. 45 (2), 327-335. http://dx.doi.org/10.1016/j.tifs.2015.04.013.

Tamayo Tenorio, A., Kyriakopoulou, K.E., Suarez-Garcia, E., van den Berg, C., van der Goot, A.J., 2018. Understanding differences in protein fractionation from conventional crops, and herbaceous and aquatic biomass - consequences for industrial use. Trends Food Sci. Technol. 71, 235-245. http://dx.doi.org/10.1016/j.tifs.2017. 11.010. 